\title{
Visual Digitized Artwork for Archiving Model of Sustainable Context
}

\author{
Rafeah Legino ${ }^{1,2}$, Muhamad Khairi Shamsudin², Farid Raihan Ahmad², Mursyidah Zainal Abidin² \\ ${ }^{1}$ Formgiving Research Group, Faculty of Art \& Design, Universiti Teknologi MARA, Shah Alam 40450 Selangor, Malaysia \\ ${ }^{2}$ Fine Art Department, Faculty of Art \& Design, Universiti Teknologi MARA, Shah Alam 40450 Selangor, Malaysia
}

rafeahl@uitm.edu.my, khairi9542@uitm.edu.my, farid813@uitm.edu.my, mursyidah@uitm.edu.my

Tel of 1st Author: +60173680870

\begin{abstract}
This project reviewed on the artwork that exhibited in galleries is always in danger of being deteriorated due to exposure or the unconducive environment unless a good system of preserving them is in place. The valuable artwork must protect, and therefore a useful archiving technology needs to be engaged for the perpetual digitalized artwork. This project was able to digitalize for constant archiving of artwork that contains various themes, styles, content and context from a different medium. The identification is essential due to categorizing the types of material, including physical and visual protection through digitations.
\end{abstract}

Keywords: Archiving; Artwork; Digitized; Sustainable Context; Visual

eISSN: 2398-4287 @ 2021. The Authors. Published for AMER ABRA cE-Bs by e-International Publishing House, Ltd., UK. This is an open access article under the CC BYNC-ND license (http://creativecommons.org/licenses/by-nc-nd/4.0). Peer-review under responsibility of AMER (Association of Malaysian Environment-Behaviour Researchers), ABRA (Association of Behavioural Researchers on Asians) and cE-Bs (Centre for Environment-Behaviour Studies), Faculty of Architecture, Planning \& Surveying, Universiti Teknologi MARA, Malaysia.

DOI: https://doi.org/10.21834/ebpj.v6iSI5.2944

\subsection{Introduction}

This study defines the current scenario, where visual digitized, enhanced potential profiling systems in artistic genres. The artwork was created by the artist and deals with the likely industry for commercial and innovation purposes. Every artist represents their creativity through artwork and comprises themes, style, content, and context that follow the appropriate method in their making. This project release from a related literature review expands with reflection on how the previous and recent approaches and obtains digitalization needs comprehensively. This review clearly defines how digitized was implemented within the digital function to preserve institutional repository preserving and maintaining culture-the practical implications of long-term digital archiving processes in national or international views. The advantage of digital technology is already well-known all over the globe. When referring to the current studies, of course, we will refer to what kind of improvement that had developed. So far, the study that had been established is only focused on a particular scenario like digital heritage systems that provide a new framework to support the narrative exhibition in London (Wang, 2018).

On the other hand, digitalization technology is also standard in European galleries, libraries, archives and museums of text, images and other resources (Lutz, 2017). The phenomena show how the practice and digital function are resolved critical research and the evolving professional work changes in their country. However, in our country, visual digitalization that is involved with our cultural heritage is highly required. Therefore, this study enhances the visually digitized cultural heritage archiving framework for the preservation and

eISSN: 2398-4287 @ 2021. The Authors. Published for AMER ABRA cE-Bs by e-International Publishing House, Ltd., UK. This is an open access article under the CC BYNC-ND license (http://creativecommons.org/licenses/by-nc-nd/4.0/). Peer-review under responsibility of AMER (Association of Malaysian Environment-Behaviour Researchers), ABRA (Association of Behavioural Researchers on Asians) and cE-Bs (Centre for Environment-Behaviour Studies), Faculty of Architecture, Planning \& Surveying, Universiti Teknologi MARA, Malaysia.

DOI: https://doi.org/10.21834/ebpj.v6iSl5.2944 
provides new economic opportunities and links with the industry. At the same time, this initiative is attached closely to the technology that encompasses the transformation from traditional, which changes to the new economy knowledge-intensive digitalization that essential for detaining the cultural heritage objects? Why cultural heritage had to be considered significant and then had to transfer into virtual digitalization documentation? How to design an appropriate model of visual digitalization for detaining the cultural heritage when a disaster occurs? This study purposely retains the cultural heritage objects into visual digitalization for constant archiving of cultural artefacts. At the same time, this study associated with categorizing and classifying selected examples of heritage objects to redraw and formulate into virtual digitalization data. This study will construct a completed and appropriate new framework that prioritizes the conservation strategy and addresses the basic guideline in visual digitalization approaches at the end of this project.

\subsection{Related Literature Review}

Today, digital technologies are encroaching on all areas of cultural life, including the preservation and conservation institutions. The fast-paced development of digital technologies professed various types of digital technology between material artefacts that challenge museums. Therefore, in the twentieth century, museums have collaborated with artists and other creative people inspired by their collections or as guest curators. The teamwork program with the artists can be used as a model to foster improvement strategy in museums and to promote museum's collections (Abreu et al., 2016). On the other hand, the ecological needs for the proper protection of artefacts are usually inconsistent with those for visitors to archaeology museums. The outcomes suggested how the air curtain and capillary radiant coupled heating system was a feasible and energy-efficient approach for the ecosystem needed to safeguard the historical relics (Xiao et al., 2016). Besides, the project that was successfully enhanced in the Norwegian State shows how the artefacts are highly acidic and have notably reduced mechanical strength. Indeed, the outcome was In line with the use of non-aqueous alkaline nanoparticle dispersions that have offered effective results for the protection of cellulose-based materials (Andriulo et al. 2016).

Collections of visual digitization of cultural heritage artefacts or objects that deteriorated or destroyed will make the most effective use of valuable and usable technology. A digital version may someday be the only record of an original object using original copying materials that will require preservation. For digitizing heritage monuments, it needs a process of spatial data acquisition, geometry modelling, digital archiving, and web-based representation (Cheng, 2012). Using digital technology for cultural heritage documentation Is a global trend in the 21 st century. There is a need for a system to manage and interpret data to preserve cultural heritage efficiently. The Integration of technology will support efficient management of databases; several benefits could be obtained from this structural standard. The study Included cultural heritage management documentation, centralized and minimized the possibility of data re-entry. Sometimes, the result was inconsistent and facilitated immediate data updating; the various data can be simultaneously retrieved and saved in real-time. The incidence of errors can be reduced later. The suitable system could be easily tailored to meet the administrative requirements for the standardization of documentation exchanged between cultural properties institutions and various countries (Ning et al., 2011). Digitization is regarded as a method of protecting and preserving cultural and historical heritage. It attempts to establish the level of development of this process in the country, to identify the good examples and information on digital presentation and preservation of cultural heritage. The digitization of the arts cannot but significantly make our lives more prosperous and more refined. In this sense, the creative wealth represented by the tradition and practice of the arts Is constitutively a part of the process of development. The feasibility of multimedia technologies to improve the efficiency of digital libraries acts as a basis for the use of the technologies of the information age and qualitative changes in all spheres of life. The recent study extended the significance of digitalization that enriched cultural to digital heritage in the European country and how digital takes much dynamic the stimulating and participating familiarity in museum or gallery exhibition. The recent study enhanced more towards scientific approaches within chemistry (Alexander \& Schiesser, 2017). Moreover, even though in India, the status of digitization has been explored, which works closely with manuscripts in India. Digitalization was chosen to transcribe the manuscripts quickly, effortlessly, and expeditiously (Gupta \& Sharma, 2017).

In Malaysia, the risk management for digital cultural heritage in providing and presenting information via electronic means and formats truly fascinates information agencies worldwide. This phenomenon affects the thinking and perception of the managers and administrators of libraries, museums, archives, and galleries. The exploration and initiatives to deliver the information, however, the extent of sustainability of those resources is unknown. The digital cultural heritage resources in a specific country are at risk regarding digitization policies, selection criteria, cost, staffing, technology, storage, metadata management and copyright. It also provides an insight to other researchers to seriously investigate other risks of digital cultural resources besides the dangers identified in this study (Manaf et al., 2013). Cultural activities are increasingly noted as drivers of meaningful development. However, they have yet to gain a prominent records preservation status in the National Museums, and Art Galleries ascertains the future of museums and galleries as information centres. Documents should be managed appropriately from the time they are created until their ultimate disposal; this study examined the preservation strategies employed to ensure their records survive into the future (Chaterera, 2013). The architecture development strategy and includes the performing arts exhibit direct effects on social progress and economic growth through trade in music, movies, and temporary work permits for artists. Indirectly, the contributions may also include environmental stewardship, tourism, nation branding, social Inclusion, cultural democracy, and shifting cultural behaviours (Kabanda, 2014). The procedure that improves the efficiency of submission of information using multimedia technology was examined in this report, thus ensuring the use of a powerful new tool for the perception of information by disabled persons. The formation peculiarities of multimedia information content for disabled persons were analyzed. This study considers the digital library an information system, where information is formed and collected from various sources, sorted, structured, and intellectually processed. Finally, it has proposed a set of Information technology services, making multimedia information content accessible for disabled persons. 


\subsection{Methodology}

The artwork archiving is reviewed then an adaptive framework for indoor and outdoor work preservation (physically and digitally) is analyzed. Although the literature review was conducted and used text analysis, the data gathered from several sources was significantly guided for the early stage. The paradigm of the digital documentation from the other development and the established project will examine as to form the ultimate framework in sustaining importance and in line with the current digital efficiency and high-tech approaches. The data and visual documentation categorized the framework of the selected themes classified as supporting a valuable work. This involves identifying, assessing, and observing, and organizing the material of the artwork. Thus, there are two aspects of artwork preservation, namely physical preservation and visual preservation through digitization. The tracing system through text analysis will support the novel design construction developed and enhanced in the following finding and discussion.

\subsection{Finding and Discussion}

As a reflection of the current situation now, this project could significantly contribute to compiling and profiling the artwork. We understand that artwork is composed for purposes and then extends to the exhibition's curatorial process that was later probably bought by an art collector. This is in how the common practice that usually extends by the artist as art creation. However, the artist is sharing their unique idea through various mediums or material, but then as to in line with technology, cooperation through digitalization is essential. The function of digital technology increases in different roles and challenges. For instance, in the UK, digital preservation was implemented for institutional repositories; however, "digital preservation is a complex process, and there are still many unsolved issues, which make it a challenging task for institutional repositories" (Hockx-Yu, 2006, p. 232). The broad deployment of institutional repositories also provides new opportunities for digital preservation. Much could be done to consider digital preservation from the outset, involve the authors, and embed digital preservation into repository workflow, which will ease the later preservation tasks, also for a specific department. The intangible cultural heritage is a source of cultural variety, and as such, it should be prioritized to preserve and maintain cultural heritage.

Nonetheless, while there has been substantial development in digitizing technology for physical, cultural assets, particularly in 3D reconstruction, the e-documentation of intangible cultural property has not kept pace. The considerable hurdles involved in the systematic e-digitisation of intangible cultural assets, such as performing arts, are fundamental causes. We provide a high-level strategy for changing intangible cultural assets, termed folk dances, into tangible choreographic digital objects (Doulamis et al., 2017). The model created in film heritage institutes has played a critical role in preserving media legacy, essential for understanding and experiencing modern society's history and aesthetics (Elsaesser, 2016). The digital model assets for almost a decade due to the widespread adoption of digital technologies in the audio-visual industries. The previous scenario, because analogue projectors are no longer available, generating digital surrogates of their analogue holdings to ensure their accessibility and circulation. Brennen and Kreiss (2014) reflected the idea of digitization as converting analogue data into digital bits. This project also refers to considerable social and institutional changes associated with digital technology in a certain sphere of activity, such as an industry or a sector of the economy, as digitalization. The consideration in long-term and meaningful conservation of digital resources is referred to as digital preservation. The practical implications of long-term digital archiving processes in organizations were debates on digital archiving and digital sustainability. Digital sustainability is identified based on technical, social, and economic concerns and user considerations. Overall, long-term digital archiving necessitates a safe, sufficient financial strategy, as well as an appropriate technology infrastructure and continuing, systemic administration of digital documents. Furthermore, a comprehensive knowledge management system that includes instructions for all workflows in the digital archiving process can support a long-term organizational infrastructure.

On the other hand, while many university libraries prioritize professional development for library staff, library directors frequently acknowledge the problems of establishing flexible, long-term professional development programmes that address library staff's different requirements and interests. We set out how to create a flexible and sustainable professional development program that could facilitate conversations about teaching and learning in our libraries. Then, the system could be inclusive of all library workers throughout our distributed, multi-branch system, with investment in professional development around online teaching and learning becoming an institutional priority upon the onset of the COVID-19. The programme design paradigm for producing inclusive and sustainable professional development programming for librarians and library staff may be applied even outside of the current restrictions that higher education faces (Carroll \& Mallon, 2021). Sustainability concepts pervade all aspects of scholarly work, but they are especially important when considering methods that rely on digital technology. Human labour and rights violations, ecological and environmental harm, carbon footprints, waste of resources related to obsolescence, and other concerns that touch every step of the product life cycle are regularly cited as consequences of digital scholarship. However, sustainability must be viewed as an epistemic idea rooted in complex systems rather than a collection of issues handled by instrumental methods in operational logistics. According to this article, the intricacy of sustainability necessitates humanistic methodologies and ethical principles in judgments regarding future practice in teaching, research, and institutional settings, which challenges mechanical approaches to sustainability (Drucker, 2021). 
This study aims to figure out how to adapt teaching and learning approaches for new digital natives to increase their commitment to sustainable development. The study investigates if there is a link between digital natives' features, individual dynamic capacities, and their dedication to innovation and, as a result, sustainability (Bagur-Femenías et al., 2020). The functional model of using visualization and digitalization for media literacy development in the media education process, when it comes to the media's role in educational planning, refers to media education as a part of the contemporary science of mass media and mass communication. The functional paradigm of using visualization and digitalization in current media education is discussed in this study. The notion of visual cognition is introduced in the context of "media education." Object identification, attention and search, word recognition and reading, eye movement control and active vision, short-term and long-term memory for long-term memory, and visual imagery creation are all parts of visual cognition. Cognition describes how a person receives and processes information; people with a visual cognitive style prefer to process visual information over spoken information. The research considers a variety of visual data processing techniques. In today's media, the phenomenon of media literacy is highlighted. The use of visualization as a strategy for "packing" education with media potential is being investigated. The importance of visual communications in the media is highlighted. The effectiveness show amassed how the media was competent to the student audience, including future journalists, producers, filmmakers, and designers. The taught can create modern print and online media based on an analysis of different approaches to education (Makarova, 2019). In the age of social media and digital surroundings, considerable sustainable tourism creative initiatives are needed. Because the heart of a trip is an exceptional experience, one of the competitive advantages for meeting those demands is the authentication of tourist sites. So many tourist sites operate and expand in ways that are unsustainable in terms of the environment. Through digital technology is given the ease of access provided by social media, tourist players only strive for excellence in business and management (Laxmita et al., 2021). The decision to retain something and incorporate it into cultural memory is an act of power, as Jacques Derrida remarked in Archive Fever. Even though traditional archive practices favour institutional documents retained in their original arrangement, post-modern critiques such as Derrida's have prompted researchers and archivists to devise novel techniques to describe, find, and access. These strategies have specific consequences for the archive of the performing arts. Each scholar-archivist on this panel will discuss post-modern methods in the archive setting via case studies and personal experiences (Testa et al., 2021).

\subsection{Conclusion}

To sum up, technology raised many benefits to the nation, including where the digitalization system supported the artist and the artwork. The expansion from various examples was clearly shown in how the visual digitized supported archiving artwork through a systematic process and enhanced sustainable context, which mooted valuable artwork and must protect. Therefore, a useful archiving technology needs to be engaged for the perpetual digitalized artwork. This project was inspired, and the paradigm in how to digitalize technology was constantly developed to archive artwork. Artwork contains various themes, styles, content, and context formulated from a different kind of medium. The identification is essential due to categorizing the types of material, including physical and visual protection through digitations.

\section{Acknowledgements}

The authors would like to acknowledge the Research Management Center (RMC), Universiti Teknologi MARA, for funding under the grants of the 600-IRMI/DANA 5/3/BESTARI (124/2018) for this project.

\section{References}

Abreu, R., Leite, M., Jorge, J., Grouller, F., van der Zwaag, W., leal, A., \& Figueiredo, P. \{2016). Ballistocardiogram artefact correction taking into account physiological signal preservation in simultaneous EEG-fMRI. Neuroimage.

Abd Manaf, Z., Ismail, A., Razlan, N. M., Abd Manaf, A., \& Daruis, R. (2013, May). Risk management for digital cultural heritage information in Malaysia. In International Conference on Information Management and Evaluation (p. 1). Academic Conferences International Limited.

Alexander, S. A., \& Schiesser, C. H. (2017). Heteroorganic molecules and bacterial biofilms: Controlling biodeterioration of cultural heritage. ARKIVOC: Online Journal of Organic Chemistry, 2017.

Andriulo, F., Braovac, S., Kutzke, H., Giorgi, R., \& Baglloni, P. (2016). Nanotechnologies for the restoration of alum-treated archaeological wood. Applied Physics A, 122(4), 1-9.

Antoniazzi, L. (2020). Digital preservation and the sustainability of film heritage. Information, Communication \& Society, 1-16.

Amenta, L. C. (2014). Building a Future for the Past-The Sustainability of Digital Archiving Processes in Audio-Visual Cultural Heritage Organizations (Master's thesis). 
Bagur-Femenías, L., Buil-Fabrega, M., \& Aznar, J. P. (2020). Teaching digital natives to acquire competencies for sustainable development. International Journal of Sustainability in Higher Education.

Brennen, S., \& Kreiss, D. (2014). Digitalization and digitization. Culture digitally, 8.

Chaterera, F. (2013). Beyond documentation: an analytical approach towards the future of museums as information centres (Doctoral dissertation, Midlands State University).

Cheng, H. M. (2012). The workflows of 3D digitizing heritage monuments. Laser scanner technology, 183.

Elsaesser, T. (2016). Media archaeology as a symptom. New Review of Film and Television Studies, 14(2), 181-215.

Carroll, A. J., \& Mallon, M. N. (2021). Using digital environments to design inclusive and sustainable communities of practice in academic libraries. The Journal of Academic Librarianship, 47(5), 1023

Doulamis, A. D., Voulodimos, A., Doulamis, N. D., Soile, S., \& Lampropoulos, A. (2017, February). Transforming Intangible Folkloric Performing Arts into Tangible Choreographic Digital Objects: The Terpsichore Approach. In VISIGRAPP (5: VISAPP) (pp. 451-460).

Drucker, J. (2021). Sustainability and complexity: Knowledge and authority in the digital humanities. Digital Scholarship in the Humanities.

Fachinger, J., den Exter, M., Grambow, B., Holgerson, S., Landesmann, C., Titov, M., et al. (2004). Behaviour of spent HTR fuel elements in aquatic phases of repository host rock formations, 2nd International Topical Meeting on High Temperature Reactor Technology. Beijing, China, paper \#B08.

Gupta, D. K., \& Sharma, V. (2017). Enriching and enhancing digital cultural heritage through crowd contribution. Journal of Cultural Heritage Management and Sustainable Development.

Kabanda, P. (2014). The creative wealth of nations: how the performing arts can advance the development and human progress. The World Bank

Mehdi K., \& Koorosh, A. (2015). Achievement to Environmental Components of Educational Spaces for Iranian Trainable Children with Intellectual Disability. Procedia Social and Behavioral Sciences, 201, 9-18.

Makarova, E. A., \& Makarova, E. L. (2019). The functional model of using visualization and digitalization for media literacy development in the media education process. Медиаобразование, (4).

Mettam, G. R., \& Adams, L. B. (1999). How to prepare an electronic version of your article. In B. S. Jones \& R. Z. Smith (Eds.), Introduction to the electronic age (pp. 281-304). New York: E-Publishing Inc.

Ning, Y. Y., Hua, W. K., Ming, C. H., \& Shan, H. W. (2011). The standard of management and application of cultural heritage documentation. Geoinformatics FCE CTU, 6, 354-363.

Hockx-Yu, H. (2006). Digital preservation in the context of institutional repositories. Program.

Laxmita, N. A., Setyaningsih, W., \& Purwani, O. (2021, May). Sustainable rural tourism development in the era of social media shape identities and digital discourse settings. In IOP Conference Series: Earth and Environmental Science (Vol. 778, No. 1, p. 012010). IOP Publishing.

Lutz, S. (2017). \{D1G1TAL HER1TAGE\}. From cultural to digital heritage. Hamburger Journal FüR Kulturanthropologie (HJK), (7), 3-23.

Testa, M. V., McNellis, R., Gibson, C. T., \& Wiesner, S. (2021). Session 10. Postmodernism in the Performing Arts Archive.

Wang, D. (2018). Exploring a narrative-based framework for historical exhibits combining JanusVR with photometric stereo. Neural Computing and Applications, 29(5), 1425-1432. 